Check for updates

1 Department of Primary Care and Public Health, Imperial College London

Cite this as: BMJ 2022;376:0461 http://dx.doi.org/10.1136/bmj.0461

Published: 22 February 2022

\section{Covid-19: Ending the legal requirement to self isolate puts vulnerable people at risk}

\author{
Lara Shemtob, ${ }^{1}$ Kaveh Asanati, ${ }^{1}$ Azeem Majeed ${ }^{1}$
}

The government has just announced that all covid-19 restrictions in England are set to end. Boris Johnson, the UK prime minister, told MPs that he plans to remove the remaining restrictions, including the legal requirement to self isolate for people infected with covid-19. Instead of legislation, voluntary guidance will "advise" people with covid-19 not to attend workplaces. Employers will once again need to develop and implement new rules for their workplaces when the legal requirement to self isolate with covid-19 comes to an end. They should consider carefully how to develop and implement new policies fairly and safely in the workplace so that staff and customers-particularly those who are clinically vulnerable-are not put at risk.

Presenteeism occurs when employees go to work despite not being well enough to perform their duties. The NHS is the largest employer in England and the NHS Staff Survey showed a drop in presenteeism in 2020 compared to preceding years. ${ }^{1}$ This is likely an effect of covid-19, which forced workers and employers to endorse sick leave to prevent workplace outbreaks and has therefore gone some way to changing attitudes to calling in sick. Despite this, around $40 \%$ of NHS staff surveyed still reported coming to work in 2020, despite not being well enough to work.

Reasons why employees attend work while unwell include financial pressures. Statutory sick pay (currently £96.35 per week in England) is the minimum amount employers must pay to unwell employees; though not all workers are entitled to statutory sick pay-loopholes include agency work and zero hour contracts in certain situations. ${ }^{2}$ Though some workers are entitled to contractual sick pay which is closer to their normal salary, for many workers in England, taking sick leave means taking home less money; and sometimes no money at all.

Now that the legal requirement to self isolate will be scrapped, the government has announced that they will return to pre covid provisions of sick pay, with self isolation payments ending. Statutory sick pay and employment support will no longer be paid immediately, but only after four and seven days of absence. Workers who voluntarily decide to self isolate, but are unable to work from home, will in some cases face a loss in pay. The end to financial support for people to self isolate, or take sick leave, is concerning as people will no longer be financially supported to stay at home if they are ill. Those workers who are unable to work from home are more likely to be older, from lower socio-economic groups, and from ethnic minority backgrounds-factors that have cumulatively contributed to a higher occupational risk of death from covid-19 over the last two years. 3

The need for local health and safety policies will also leave employers with a dilemma. Should employers develop internal policies mandating self isolation for those infected with covid-19 to protect their workforce and their customers? The Health and Safety at Work Act 1974 places responsibility upon employers to ensure "as far as reasonably practicable" that both employees and non-employees are protected from workplace risks. ${ }^{4}$ The Equality Act 2010 mandates that employers make "reasonable adjustments" for employees with disability to protect them from workplace discrimination. ${ }^{5}$ For example, a retail assistant undergoing chemotherapy for cancer, for whom working from home is not possible, may be at high risk of acquiring covid-19 at work with significant medical complications now that the legislation mandating self isolation is going to be withdrawn. Who takes on the responsibility for this risk, and how can discrimination along the social gradient or against those with disability be avoided?

Presenteeism is not good for the individual attending work while unwell, nor is it good for the organisation. Covid-19, even when asymptomatic, brings risks of workplace outbreaks with significant impact on the operation of services due to sickness absences. Employers should consider workforce wide policies to encourage self isolation with fair pay when employees are infectious with covid-19, now that the legal mandate will be removed. Where this is not possible, individual occupational health risk assessments for employees vulnerable to severe covid-19 infection and its consequences should inform reasonable adjustments to their workplace duties. This will include, for example, examining how many people are allowed into the workplace at one time, ensuring good indoor ventilation, and mitigation measures such as high quality face masks are used as appropriate.

Employers will also need to consider factors such as the vaccination status of their staff and current community covid-19 infection rates in their health and safety policies. Most adults in the UK have now had two covid-19 vaccinations, but a large proportion (around one in three) have not yet come forward for a booster vaccine. Recent data show that the booster dose is essential in reducing the risk of serious illness, hospital admission, and death from a covid-19 infection caused by the omicron SARS-CoV-2 variant. Employers will need to work with their staff to promote covid-19 vaccination, but as the recent reversal in government policy for mandatory vaccination of healthcare workers shows, this is not straight forward. For the time being, community 
covid-19 rates are falling from the very high levels we saw in late 2021; and may remain at tolerable levels during the spring and summer of 2022. By next winter, however, we can expect a seasonal increase in respiratory viral infections, which will coincide with waning population immunity, placing more people at risk from covid-19.

Losing progress away from presenteeism will be a backwards step in all sectors of the economy as well as putting the most vulnerable members of society at greater risk. By ending mandatory self isolation while also removing financial support packages, the government is failing to adequately support people in lower paid occupations to protect themselves and others from covid-19, and risks widening existing socio-economic and health inequalities.

Competing interests: none declared

Provenance and peer review: not commissioned, not peer reviewed

LS is supported by a National Institute for Health Research (NIHR) Academic Clinical Fellowship. KA and AM are supported by the NIHR Applied Research Collaboration North west London. The views expressed in this publication are those of the authors and not necessarily those of the NHS, the NIHR or the Department of Health and Social Care.

1 NHS Staff Survey 2020 national dashboards. Tableau Public. https://public.tableau.com/app/profile/piescc/viz/ST20nationaldashboards_16215084823020/Aboutthesurvey

2 Statutory Sick Pay (SSP). GOV.UK. https://www.gov.uk/statutory-sick-pay

3 Build Back fairer: The COVID-19 Marmot review. https://www.health.org.uk/publications/buildback-fairer-the-covid-19-marmot-review

4 Participation E. Health and Safety at Work etc. Act 1974. Statute Law Database; https://www.legislation.gov.uk/ukpga/1974/37/contents

5 Participation E. Equality Act 2010. Statute Law Database. https://www.legislation.gov.uk/ukpga/2010/15/contents 